\title{
The prevalence and predictors of active brown adipose tissue in Chinese adults
}

\author{
Zhaoyun Zhang ${ }^{1, *}$, Aaron M Cypess ${ }^{4, *}$, Qing Miao ${ }^{1, *}$, Hongying Ye ${ }^{1}$, Chong Wee Liew ${ }^{4}$, \\ Qiongyue Zhang ${ }^{1}$, Ruidan $\mathrm{Xue}^{1}$, Shuo Zhang ${ }^{1}$, Chuantao Zuo ${ }^{2}$, Zhensheng $\mathrm{Xu}^{2}$, \\ Qiqun Tang ${ }^{3,5}$, Renming Hu' ${ }^{1}$, Yihui Guan ${ }^{2}$ and Yiming Li $^{1}$ \\ ${ }^{1}$ The Division of Endocrinology and Metabolism, the Department of Internal Medicine, ${ }^{2}$ The PET Center, Huashan \\ Hospital, Fudan University and ${ }^{3}$ Department of Biochemistry and Molecular Biology, Shanghai Medical School, \\ Fudan University, Shanghai, China, ${ }^{4}$ The Research Division, Joslin Diabetes Center, Boston, Massachusetts, USA and \\ ${ }^{5}$ The Department of Biological Chemistry, Johns Hopkins University School of Medicine, Baltimore, Maryland, USA \\ * (Z Zhang, A M Cypess and Q Miao contributed equally to this work)
}

\begin{abstract}
Objective: Previous studies have shown that active brown adipose tissue (BAT) is present in adults and may play important roles in the regulation of energy homeostasis. However, nearly every study has been carried out in patients undergoing scanning for cancer surveillance (CS), whose metabolism and BAT activity may not reflect those of healthy individuals. The objective of this study was to investigate the prevalence and predictors of active BAT in Chinese adults, particularly in healthy individuals.

Design: A total of 31088 consecutive subjects aged $\geq 18$ years who had undergone positron emission tomography/computed tomography (PET/CT) scanning of BAT were evaluated in this study.

Methods: We measured BAT activity via ${ }^{18} \mathrm{~F}$-fluorodeoxyglucose PET/CT in subjects who had undergone scanning for either a routine medical checkup (MC) or CS in Shanghai. Then, we investigated the predictors of active BAT, particularly in healthy individuals.

Results: In both groups, the prevalence of BAT was higher in women than in men. Using a multivariate logistic analysis, we found age, sex, BMI, and high thyroid glucose uptake to be significant predictors of BAT activity in the MC group. Similarly, we found age, sex, and BMI to be significant predictors of BAT activity, but not thyroid high glucose uptake, in the CS group. Conclusions: In Chinese adults, BAT activity inversely correlates with BMI and thyroid high glucose uptake, which reinforces the central role of brown fat in adult metabolism and provides clues to a potential means for treating the metabolic syndrome.

European Journal of

Endocrinology

(2014) 170, 359-366
\end{abstract}

\section{Introduction}

Mammals have two types of adipose tissue, white adipose tissue (WAT) and brown adipose tissue (BAT), which are distinct in both structure and physiological function $(1,2)$. WAT is formed by unilocular adipocytes containing a large single vacuole, while BAT is formed by multilocular adipocytes containing a large number of mitochondria (3). WAT stores energy and releases adipocytokines, which have been implicated in the impairment of insulin signaling (4). BAT plays a central role in non-shivering and diet-induced thermogenesis in small mammals (5) and is considered to be a target in the treatment of obesity (6). It was believed that in humans BAT existed only in newborns and young children and disappeared or had negligible roles in adults $(1,7)$. However, recent studies have demonstrated that active BAT is present in adult humans and its presence may be metabolically important $(8,9)$. (c) 2014 European Society of Endocrinology Printed in Great Britain 
The evidence for the presence of BAT in adult humans has come from ${ }^{18} \mathrm{~F}$-fluorodeoxyglucose $\left({ }^{18} \mathrm{~F}\right.$-FDG) positron emission tomography/computed tomography (PET/CT) scans and biopsy. PET/CT has revealed high uptake of ${ }^{18} \mathrm{~F}-\mathrm{FDG}$ in supraclavicular and paracervical regions, which were confirmed to be BAT by the detection of the mRNA and protein expression of uncoupling protein 1 (UCP1), the BAT-specific thermogenic protein $(8,9)$. The physiological significance of the presence of BAT in adult humans is not fully understood, but previous studies have provided evidence for a potential role of BAT in the regulation of body weight and energy homeostasis $(8,9,10,11)$. Thus, the presence of BAT may help to explain the inter-individual differences in metabolism with regard to weight gain in humans (12).

Despite the recent significant progress in understanding adult human BAT, little is known about the prevalence and related factors of active BAT in Chinese adults. Moreover, almost all human population studies have been carried out in subjects for cancer surveillance (CS) and thus may not reflect BAT behavior in a healthy population. In the present study, we reviewed 31088 subjects who underwent PET/CT scans at Huashan Hospital in Shanghai and further examined the determinants of active BAT in this large cohort of adults. Due to the large number of individuals in our cohort, we were able to evaluate the difference between healthy subjects presenting for a medical checkup (MC) and subjects who were scanned for CS and to clarify the impact of clinical and lifestyle parameters.

\section{Subjects and methods}

\section{Patients}

This study followed institutional guidelines and was approved by the ethical committees of Huashan Hospital in Shanghai and the Joslin Diabetes Center in Boston. As only medical records were examined, the consent of the subjects was not required. From July 2006 to June 2010, a total of 31088 consecutive subjects aged $\geq 18$ years underwent PET/CT scanning at the Huashan PET/CT center (geographical coordinates: $31^{\circ} 12^{\prime} \mathrm{N}$, $121^{\circ} 30^{\prime} \mathrm{E}$ ). These scans, which were paid for by the patients, were part of either a routine MC or CS. In China, some people believe that PET/CT scanning can sensitively detect early malignancy and request for it during a routine MC. All the scans were obtained using a Siemens Biograph 64 PET/CT scanner.

\section{Data collection}

Data on age, imaging date, sex, and outdoor temperature were collected for all the 31088 subjects. Outdoor temperatures in Shanghai for the imaging dates were obtained from the Chinese Meteorological Administration. To evaluate the effects of multiple metabolic parameters on BAT activity, we collected data on height, body weight, fasting plasma glucose (FPG), medical history, diagnosis, liver triglyceride content, and thyroid metabolic activity for all the subjects with detectable BAT and their negative controls, consisting of two subjects who underwent PET/CT scanning on the same day but without detectable BAT.

\section{PET/CT scanning and image reconstruction}

Before PET/CT scanning, the subjects were asked to fast for $8 \mathrm{~h}$, but they had free access to water. After the i.v. injection of $5.55-7.40 \mathrm{MBq} / \mathrm{kg}$ of ${ }^{18} \mathrm{~F}-\mathrm{FDG}$, the subjects rested comfortably, with the head, neck, and shoulders supported from the outset of the experiment to the start of the imaging. Room temperature was $21-23^{\circ} \mathrm{C}$. Imaging was performed in a three-dimensional mode, with emission scans of $1.5 \mathrm{~min}$ per bed position. The CT scan was used for attenuation correction and ${ }^{18}$ F-FDG uptake site localization. Both image sets were reconstructed as transaxial, coronal, and sagittal images with a slice thickness of $2 \mathrm{~mm}$. More than three nuclear medicine physicians interpreted the PET/CT images using OpenPACS and PET/CT Viewer shareware (8). Each of the physicians reviewed all the cases separately and then discussed and reached the final consensus.

Active BAT was considered present if there were areas of tissues that were more than $4 \mathrm{~mm}$ in diameter, had the CT density of adipose tissue ( -250 to $-50 \mathrm{HU})$, and had a maximum standard uptake value (SUVmax) of ${ }^{18} \mathrm{~F}$-FDG of at least $2.0 \mathrm{~g} / \mathrm{ml}$ (Supplementary Figure 1A, see section on supplementary data given at the end of this article). This cutoff represented the lower boundary of activity in subjects with detectable BAT according to a previous study, and it was more than 2 s.D. above the SUVmax observed in typical depots of WAT (8).

To examine liver triglyceride content, images from CT scans at thoracic vertebra 11 to 12 were reviewed (Supplementary Figure 1B). CT attenuation was determined in four regions of interests (ROIs) for both liver and spleen, with each ROI being $120 \mathrm{~mm}^{2}$. ROIs for liver were selected manually to avoid major vessels. The average $\mathrm{HU}$ was used to calculate the liver-to-spleen ratio 
(L:S ratio). Fatty liver was defined as $\mathrm{HU}<50$ or L:S $<1$ (Supplementary Figure 1C) $(13,14)$.

Thyroid glucose uptake was evaluated using the local SUVmax of PET scans. A SUVmax of thyroid $>2.5$ was considered high glucose uptake $(15,16,17)$.

\section{Statistical analysis}

Data were analyzed using the SAS software, version 9.1 (SAS Institute Inc., Cary, NC, USA). Normally distributed continuous variables were compared between the study groups with Student's $t$-test, and non-normally distributed continuous variables were compared with the MannWhitney $U$ test. The roles of sex, age, BMI, cancer diagnosis, fatty liver, and thyroid high glucose uptake as predictors of substantial BAT were tested by logistic regression with both univariate and multivariate models.

The subjects were divided into groups corresponding to the upper, middle, and lower thirds of the values for age, BMI, and plasma glucose levels; the significance of linear trends across the thirds was tested by assigning each participant the median value for the third and modeling this value as a continuous variable. Missing values for plasma glucose were assigned to the middle third. Odds ratios and 95\% CIs were estimated as measures of the magnitude of the associations. All $P$ values presented are two-tailed, and values $<0.05$ are considered to be statistically significant.

\section{Results}

\section{Prevalence, age, body weight, and sexual dimorphism of BAT}

Of the 31088 subjects, 410 (1.32\%) had tissue that was identified by PET/CT scanning as active BAT, the prevalence of which ranged from 1.3 to $6.7 \%$ shown in previous retrospective studies $(8,18,19,20)$. The prevalence of detectable BAT in the MC group was $1.58 \%$ (264 of 16 699), while it was $1.01 \%$ (146 of 14389 ) in the CS group (Fig. 1A). In both the MC and CS groups, the prevalence of active BAT was higher in women than in men (3.16 vs $0.77 \%, P<0.001 ; 1.59$ vs $0.61 \%, P<0.001$; Fig. 1B). The association between the prevalence of active BAT and mean monthly temperature was evaluated by logistic regression. In both the MC $(r=-0.759, P<0.001)$ and CS $(r=-0.227, P=0.196)$ groups, the probability of detecting BAT decreased with increasing outdoor temperature (Supplementary Figure 2, see section on supplementary data given at the end of this
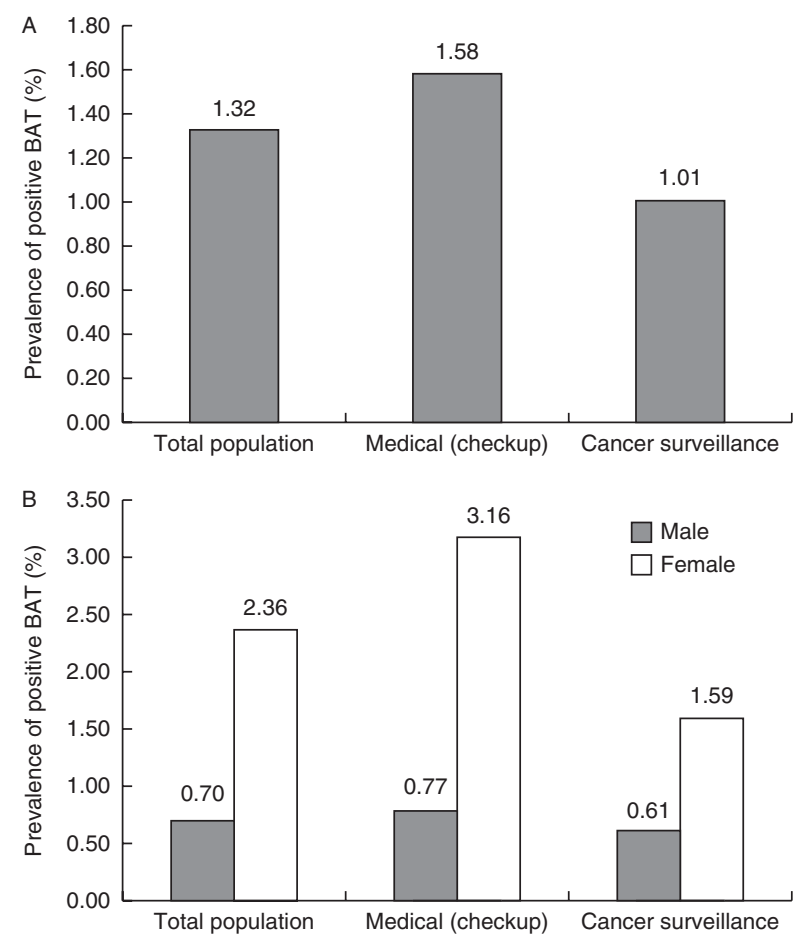

\section{Figure 1}

Prevalence of active BAT in both cancer surveillance patients and medical checkup subjects. (A) Prevalence of active BAT in all adult subjects $(1.32 \%)$, cancer surveillance patients $(1.01 \%)$ and medical checkup subjects $(1.58 \%)(P<0.001$, medical checkup vs cancer surveillance). (B) Prevalence of active BAT in men and women. In both cancer surveillance patients and medical checkup subjects, the prevalence of detectable BAT was higher in women than in men (1.59 vs $0.61 \%$; 3.16 vs $0.77 \%$, $P<0.0001$, respectively).

article). In both groups, the average age of BAT-negative subjects was higher than that of BAT-positive subjects ( $47.78 \pm 9.45$ vs $40.00 \pm 8.17$ years, $P<0.0001 ; 55.2 \pm 14.12$ vs $43.7 \pm 13.38$ years, $P<0.0001$, respectively, Supplementary Table 1 , see section on supplementary data given at the end of this article). In addition, in both groups, body weight was higher in BAT-negative subjects than in BAT-positive subjects $(68.78 \pm 12.51$ vs $58.47 \pm$ $10.13 \mathrm{~kg}, P<0.001 ; 63.10 \pm 11.56$ vs $58.20 \pm 9.10 \mathrm{~kg}$, $P<0.001$, Supplementary Table 1 ).

\section{Anthropometric and metabolic predictors of active BAT}

Additional predictors of a high mass of detectable BAT were estimated by examining the association of BAT with sex, age, BMI, and FPG in the 410 subjects who had detectable BAT and a sample of 818 date-matched control 
subjects who did not have active BAT (Table 1). All these parameters were significantly different between the BATpositive and BAT-negative subjects in both the MC and CS groups (Tables 2 and 3). In the univariate analyses of MC subjects (Table 4), BAT was more likely to be detected in women $(P<0.0001)$, patients in the bottom third for age (age below 39.2 years) $(P<0.0001)$, the thinnest patients $(P<0.0001)$, and those who had no fatty liver $(P<0.0001)$ (Table 4$)$. The univariate analyses of CS patients yielded similar results (Table 5).

In age- and sex-adjusted multivariate analyses, BMI in the CS patients remained significant (Table 5 and Supplementary Figure 3, see section on supplementary data given at the end of this article), while age, BMI, and thyroid glucose uptake in the MC subjects remained statistically significant (Table 4 and Supplementary Figure 3). The likelihood of having detectable BAT was greater in the least obese subjects by a factor of $\sim 4$ and in
Table 2 Clinical characteristics of BAT-positive subjects and date-matched negative controls in the medical checkup group. Data are presented as $n(\%)$ or as mean \pm S.D.

\begin{tabular}{|c|c|c|c|}
\hline \multirow[b]{2}{*}{ Characteristics } & \multicolumn{3}{|c|}{ Medical checkup } \\
\hline & $\begin{array}{l}\text { BAT negative } \\
\quad(n=528)\end{array}$ & $\begin{array}{l}\text { BAT positive } \\
\quad(n=264)\end{array}$ & $P$ value \\
\hline Female & $223(42.40)$ & $179(67.80)$ & $<0.0001$ \\
\hline Age (years) & $44.58 \pm 8.06$ & $40.00 \pm 8.17$ & $<0.0001$ \\
\hline Age (years; tertiles) & & & $<0.0001$ \\
\hline$<39.2$ & $140(26.52)$ & $130(49.24)$ & \\
\hline $39.2-45.7$ & $218(41.29)$ & $85(32.20)$ & \\
\hline$>45.7$ & $170(32.20)$ & $49(18.56)$ & \\
\hline BMI $\left(\mathrm{kg} / \mathrm{m}^{2}\right)$ & $24.80 \pm 3.22$ & $21.10 \pm 2.46$ & $<0.0001$ \\
\hline BMI ( $\mathrm{kg} / \mathrm{m}^{2} ;$ tertiles) & & & $<0.0001$ \\
\hline$<21.7$ & $92(17.42)$ & $164(62.12)$ & \\
\hline $21.7-25.0$ & $182(34.47)$ & $82(31.06)$ & \\
\hline$>25.0$ & $254(48.11)$ & $18(6.82)$ & \\
\hline Glucose $(\mathrm{mmol} / \mathrm{l})$ & $5.05 \pm 0.85$ & $4.88 \pm 0.52$ & 0.0006 \\
\hline Glucose (mmol/l; tertiles) & & & 0.2789 \\
\hline$<4.7$ & $192(36.50)$ & $110(41.98)$ & \\
\hline $4.7-5.0$ & $177(33.65)$ & 77 (29.39) & \\
\hline$>5.0$ & $157(29.85)$ & $75(28.63)$ & \\
\hline
\end{tabular}

by a factor of $\sim 2$ (Tables 4 and 5 ). Thus, BAT was most frequently found in young women who had a lower BMI.

Further analyses were carried out in women. In the univariate analyses, age $(P=0.002)$, BMI $(P<0.0001)$, fatty liver $(P<0.0001)$, and thyroid high glucose uptake $(P=0.025)$ were significant. In age-adjusted multivariate analyses, BMI $(P<0.0001)$ and thyroid high glucose uptake $(P=0.009)$ remained significant (Table 6$)$. The results were the same as those obtained for the total population.

\section{MC vs CS subjects}

Of the 410 subjects in the BAT-positive cohort, 264 (64.39\%) did not have a diagnosis of cancer and underwent PET/CT scanning as part of a routine MC. There were two differences between the CS patients and the MC subjects. The MC subjects in the BAT-positive cohort were younger (40.00 vs 43.70 years, $P=0.0027$ ) and had lower FPG levels (4.88 vs $4.99 \mathrm{mmol} / \mathrm{l}, P=0.0330$ ) (Table 1 ).

\section{Discussion}

Obesity is a significant cause of morbidity and mortality, and recently, there has been considerable interest in studying the physiology of BAT in humans, given its protective role against obesity in animal studies $(21,22)$. Recently, several studies have led to a paradigm shift in our comprehension of the potential role of BAT in 
Table 3 Clinical characteristics of BAT-positive patients and date-matched negative controls in the cancer surveillance group. Data are presented as $n(\%)$ or as mean \pm S.D.

\begin{tabular}{|c|c|c|c|}
\hline \multirow[b]{2}{*}{ Characteristics } & \multicolumn{3}{|c|}{ Cancer surveillance } \\
\hline & $\begin{array}{l}\text { BAT negative } \\
\quad(n=292)\end{array}$ & $\begin{array}{l}\text { BAT positive } \\
\quad(n=146)\end{array}$ & $P$ value \\
\hline Female & $136(46.58)$ & $94(64.38)$ & 0.0004 \\
\hline Age (years) & $45.67 \pm 10.62$ & $43.70 \pm 13.38$ & 0.1216 \\
\hline Age (years; tertiles) & & & 0.0085 \\
\hline$<39.7$ & $80(27.40)$ & $59(40.41)$ & \\
\hline $39.7-50.7$ & $75(25.68)$ & $33(22.60)$ & \\
\hline$>50.7$ & $137(46.92)$ & 54 (36.99) & \\
\hline BMI $\left(\mathrm{kg} / \mathrm{m}^{2}\right)$ & $24.27 \pm 3.39$ & $21.00 \pm 2.43$ & $<0.0001$ \\
\hline BMI (kg/m²; tertiles) & & & $<0.0001$ \\
\hline$<21.5$ & $64(21.92)$ & $88(60.27)$ & \\
\hline $21.5-24.7$ & $97(33.22)$ & $52(35.62)$ & \\
\hline$>24.7$ & $131(44.86)$ & $6(4.11)$ & \\
\hline Glucose $(\mathrm{mmol} / \mathrm{l})$ & $5.23 \pm 0.98$ & $4.99 \pm 0.50$ & 0.0011 \\
\hline Glucose (mmol/l; tertiles) & & & 0.2337 \\
\hline$<4.8$ & 94 (32.87) & 47 (33.57) & \\
\hline $4.8-5.3$ & $68(23.78)$ & $46(32.86)$ & \\
\hline$>5.3$ & $124(43.36)$ & $47(33.57)$ & \\
\hline
\end{tabular}

adult humans. A greater understanding of BAT function could thus help us to develop treatment strategies for obesity, especially as many studies have shown both retrospectively $(8,18)$ and prospectively $(23)$ that there is an inverse correlation between BAT activity and obesity. However, the retrospective studies have been carried out in patients with a history of cancer and in cohorts that were of mostly European descent, and the prospective studies, to date, have been too small and carried out in only healthy volunteers, so our understanding of BAT activity remains inadequate in large, healthy populations and in the Chinese population, in particular.

PET/CT scanning has long been used to stage cancers. Recently, it has been used to detect malignant cancers in asymptomatic individuals (24). In China, some people request PET/CT scanning and pay for it themselves as part of their routine checkup, as they think it to be an early and sensitive way to detect malignancy. The present study took advantage of this fact and included 16699 healthy subjects. To our knowledge, this study is the largest of its kind to document the prevalence and predictors of active BAT in healthy adults. We found substantial accumulation of BAT in $1.32 \%$ of subjects - a lower prevalence than has been shown in previous studies $(8,25)$. Factors such as race, region, underlying disease, type and size of study, and ambient temperature probably contributed to the different outcomes. The significantly lower prevalence of detectable BAT in the CS group than in the MC group (1.01 vs $1.58 \%, P<0.001)$ may have resulted from the latter being a younger cohort, though other metabolic parameters should also be considered. Our results also suggest that despite some quantitative differences between the CS and MC groups, most of the findings are qualitatively similar, including age, sex, and BMI. This indicates that studies carried out in CS patients are probably reflective of the general population.

In unstimulated conditions, the reported prevalence of active BAT in previous studies was $4.6-6.8 \%(8,25,26)$, which is higher than that $(1.32 \%, 410$ of 31088 subjects $)$ reported herein. As it has been shown that ambient

Table 4 Predictors of detectable BAT based on PET/CT scanning in the medical checkup subjects. Logistic regression is based on the age- and sex-adjusted results.

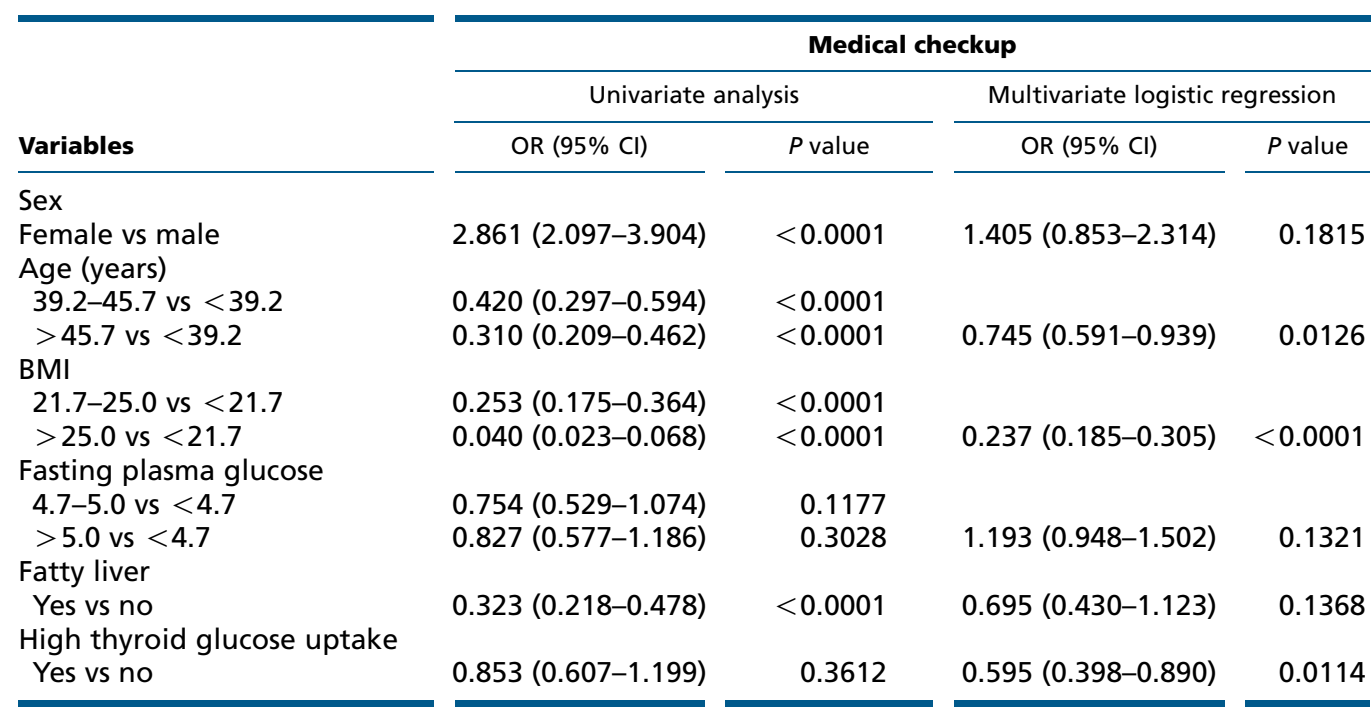


Table 5 Predictors of detectable BAT based on PET/CT scanning in the cancer surveillance patients. Logistic regression is based on the age- and sex-adjusted results.

\begin{tabular}{|c|c|c|c|c|}
\hline \multirow[b]{3}{*}{ Variables } & \multicolumn{4}{|c|}{ Cancer surveillance } \\
\hline & \multicolumn{2}{|c|}{ Univariate analysis } & \multicolumn{2}{|c|}{ Multivariate logistic regression } \\
\hline & OR $(95 \% \mathrm{Cl})$ & $P$ value & OR $(95 \% \mathrm{Cl})$ & $P$ value \\
\hline \multicolumn{5}{|l|}{ Sex } \\
\hline \multicolumn{4}{|l|}{ Age (years) } & 0.8546 \\
\hline $39.7-50.7$ vs $<39.7$ & $0.597(0.351-1.013)$ & 0.0561 & & \\
\hline $\begin{array}{l}>50.7 \text { vs }<39.7 \\
\text { BMI }\end{array}$ & $0.534(0.337-0.847)$ & 0.0077 & $0.976(0.736-1.295)$ & 0.8683 \\
\hline $21.5-24.7$ vs $<21.5$ & $0.390(0.245-0.621)$ & $<0.0001$ & & \\
\hline$>24.7$ vs $<21.5$ & $0.033(0.014-0.080)$ & $<0.0001$ & $0.221(0.155-0.316)$ & $<0.0001$ \\
\hline \multicolumn{5}{|l|}{ Fasting plasma glucose } \\
\hline $4.8-5.3$ vs $<4.8$ & $1.276(0.773-2.106)$ & 0.3396 & & \\
\hline$>5.3$ vs $<4.8$ & $0.715(0.446-1.148)$ & 0.1647 & $1.058(0.788-1.421)$ & 0.7062 \\
\hline \multicolumn{5}{|l|}{ Fatty liver } \\
\hline Yes vs no & $0.360(0.207-0.628)$ & 0.0003 & $0.646(0.335-1.246)$ & 0.1923 \\
\hline \multicolumn{5}{|l|}{ High thyroid glucose uptake } \\
\hline Yes vs no & $1.086(0.703-1.679)$ & 0.7097 & $0.672(0.392-1.152)$ & 0.1485 \\
\hline
\end{tabular}

temperature and photoperiod are correlated with the prevalence of active BAT, the difference in prevalence can at least partially be attributed to the different locations. The latitudes of the three locations where previous studies have been carried out are higher than that of Shanghai, China, while the mean annual temperature is $11^{\circ}$ in Boston, $5^{\circ}$ in Sherbrooke, $9^{\circ}$ in Nottingham, and $16^{\circ}$ in Shanghai (Supplementary Table 2, see section on supplementary data given at the end of this article). Shanghai has the warmest climate among these four locations. Consistent with previous findings $(25,26)$, in the present study, we also demonstrated an inverse correlation between the prevalence of detectable BAT and mean monthly temperature. In addition to the location and temperature, ethnicity may also contribute to the difference in the prevalence between the studies.

The present study also found significantly increased prevalence of BAT in female subjects, which is consistent with the findings of other studies $(8,18)$. This sex-based difference is also observed in rodents, where female rats

Table 6 Predictors of detectable BAT based on PET/CT scanning in women. Logistic regression is based on the age-adjusted results.

\begin{tabular}{|c|c|c|c|c|}
\hline \multirow[b]{3}{*}{ Variables } & \multicolumn{4}{|c|}{ Women } \\
\hline & \multicolumn{2}{|c|}{ Univariate analysis } & \multicolumn{2}{|c|}{ Multivariate logistic regression } \\
\hline & OR $(95 \% \mathrm{Cl})$ & $P$ value & OR $(95 \% \mathrm{Cl})$ & $P$ value \\
\hline $\begin{array}{l}\text { Purpose: Medical checkup vs } \\
\text { cancer surveillance }\end{array}$ & $1.150(0.796-1.662)$ & 0.455 & $1.103(0.689-1.766)$ & 0.684 \\
\hline \multicolumn{5}{|l|}{ Age (years) } \\
\hline $40-47$ vs $\leq 39$ & $0.476(0.298-0.762)$ & 0.002 & & \\
\hline$\geq 48$ vs $\leq 39$ & $0.564(0.353-0.901)$ & 0.017 & $0.888(0.472-1.671)$ & 0.713 \\
\hline \multicolumn{5}{|l|}{ BMI } \\
\hline $\begin{array}{l}20.9-24.20 \text { vs }<20.08 \\
>24.20 \text { vs }<20.08\end{array}$ & $\begin{array}{l}0.514(0.313-0.846) \\
0.024(0.008-0.070)\end{array}$ & $\begin{array}{c}0.009 \\
<0.0001\end{array}$ & $0.023(0.007-0.069)$ & $<0.0001$ \\
\hline \multicolumn{5}{|l|}{ Fasting plasma glucose } \\
\hline $4.8-5.1$ vs $<4.7$ & $0.905(0.580-1.413)$ & 0.662 & & \\
\hline$>5.1$ vs $<4.7$ & $0.821(0.514-1.311)$ & 0.409 & $1.326(0.745-2.361)$ & 0.337 \\
\hline \multicolumn{5}{|l|}{ Fatty liver } \\
\hline $\begin{array}{l}\text { Yes vs no } \\
\text { High thyroid glucose uptake }\end{array}$ & $0.340(0.187-0.816)$ & $<0.0001$ & $0.610(0.290-1.280)$ & 0.191 \\
\hline Yes vs no & $0.632(0.423-0.944)$ & 0.025 & $0.490(0.287-0.836)$ & 0.009 \\
\hline
\end{tabular}


have higher levels of UCP1 in the interscapular BAT depot than males when housed at the same temperature, suggesting that they may have a lower threshold temperature for cold-induced thermogenesis (27). BAT also expresses estrogen receptors, which may further explain these differences (1), as the decrease in sex hormone levels with increased age could be a cause of BAT atrophy. As a result, postmenopausal women will be in a metabolic state with an increased propensity to develop obesity (28). Interestingly, BMI was lower in BAT-positive subjects than in BAT-negative subjects in both MC and CS groups, which could be highly relevant in terms of human energy expenditure. Thus, BAT was most frequently found in young healthy women with a lower BMI who were studied during colder days.

BAT-positive subjects in the MC group were younger than those in the CS group. Cancer usually occurs in older people; thus, it is easy to understand the lower age in the $\mathrm{MC}$ group. The findings in the MC group were more representative of the general population than those in the CS group.

In the MC group, there appeared to be an inverse correlation between the probability of detecting BAT and thyroid high glucose uptake in the multivariate analyses $(P=0.0114)$. Thyroid hormones are known to be the main regulators of heat generation during shivering and nonshivering cold adaptation (5). When exposed to cold or a lower temperature after meals, the expression of UCP1 is induced by the synergistic action of norepinephrine and thyroid hormones in animals (1). But it is unclear what effect thyroid hormones have on BAT activity in adult humans. Skarulis et al. (29) have shown that levothyroxine replacement increased ${ }^{18}$ F-FDG uptake in BAT in a hypothyroid patient. Consistent with the PET/CT data, both the suprascapular and periumbilical adipose tissue samples of the patient exhibited significant type 2 deiodinase (D2) activity, which was not present in a control sample obtained from another subject. In the present study, the PET/CT assessment of thyroid glucose uptake had high sensitivity, but poor specificity. It cannot reflect the thyroid hormones levels directly. Moreover, BAT expresses D2, which converts $T_{4}$ into active $T_{3}$, so thyroid gland glucose uptake and serum thyroid hormone levels may not reflect the microenvironment of the brown adipocytes. Further studies are required to understand the effect of thyroid hormones on human BAT activity.

In summary, our very large retrospective study demonstrates that the parameters affecting the detection of BAT activity are similar in both healthy subjects undergoing PET/CT scanning for a MC and those patients being scanned for CS. Detectable BAT activity positively correlates not only with more fixed parameters such as climate, age, and sex, but also with factors that can be modified, including BMI, liver fat content, and liver triglyceride content. Given the metabolic benefits observed in animal models with BAT activity, the present study reinforces the goal of increasing BAT mass and activity through both lifestyle and pharmacological interventions as a potential way to treat obesity and its associated metabolic complications.

\section{Supplementary data}

This is linked to the online version of the paper at http://dx.doi.org/10.1530/ EJE-13-0712.

\section{Declaration of interest}

The authors declare that there is no conflict of interest that could be perceived as prejudicing the impartiality of the research reported.

\section{Funding}

This work was supported by the National Natural Science Foundation of China (No. 30771024, No. 30900502, No. 30800344, and No. 81070680), the Shanghai Committee of Science and Technology, China (No. 10JC1401002 and No. 11PJ1402000), the National Basic Research Program of China (973 Program) (No. 2011CB910201), the 985 Project (III-YFX0302), the Shanghai Municipal Health Bureau (No. XYQ2011002), the Specialized Research Fund for the Doctoral Program of Higher Education (State Education Ministry 131), and the NIH grants DK046200, DK081604 (A M Cypess), and P30 DK036836 from the National Institute of Diabetes and Digestive and Kidney Diseases (NIDDK) and the Eli Lilly Foundation. The content is solely the responsibility of the authors and does not necessarily represent the official views of the National NIDDK or the NIH.

\section{Acknowledgements}

The authors thank Dr Karen K Miller for helpful comments and manuscript editing.

\section{References}

1 Cannon B \& Nedergaard J. Brown adipose tissue: function and physiological significance. Physiological Reviews 200484 277-359. (doi:10.1152/physrev.00015.2003)

2 Rosen ED \& Spiegelman BM. Adipocytes as regulators of energy balance and glucose homeostasis. Nature 2006444 847-853. (doi:10.1038/ nature05483)

3 Wu Z, Puigserver P, Andersson U, Zhang C, Adelmant G, Mootha V, Troy A, Cinti S, Lowell B, Scarpulla RC et al. Mechanisms controlling mitochondrial biogenesis and respiration through the thermogenic coactivator PGC-1. Cell 199998 115-124. (doi:10.1016/S00928674(00)80611-X)

4 Rasouli N \& Kern PA. Adipocytokines and the metabolic complications of obesity. Journal of Clinical Endocrinology and Metabolism 200893 S64-S73. (doi:10.1210/jc.2008-1613) 
5 Silva JE. Thermogenic mechanisms and their hormonal regulation. Physiological Reviews 200686 435-464. (doi:10.1152/physrev.00009. 2005)

6 Lowell BB \& Spiegelman BM. Towards a molecular understanding of adaptive thermogenesis. Nature $2000 \mathbf{4 0 4}$ 652-660.

7 Cunningham S, Leslie P, Hopwood D, Illingworth P, Jung RT, Nicholls DG, Peden N, Rafael J \& Rial E. The characterization and energetic potential of brown adipose tissue in man. Clinical Science 1985 69 343-348.

8 Cypess AM, Lehman S, Williams G, Tal I, Rodman D, Goldfine AB, Kuo FC, Palmer EL, Tseng YH, Doria A et al. Identification and importance of brown adipose tissue in adult humans. New England Journal of Medicine 2009360 1509-1517. (doi:10.1056/ NEJMoa0810780)

9 Virtanen KA, Lidell ME, Orava J, Heglind M, Westergren R, Niemi T, Taittonen M, Laine J, Savisto NJ, Enerback S et al. Functional brown adipose tissue in healthy adults. New England Journal of Medicine 2009 360 1518-1525. (doi:10.1056/NEJMoa0808949)

10 Stefan N, Pfannenberg C \& Haring HU. The importance of brown adipose tissue. New England Journal of Medicine 2009361 416-417 author reply 418-421.

11 Seale P \& Lazar MA. Brown fat in humans: turning up the heat on obesity. Diabetes 200958 1482-1484. (doi:10.2337/db09-0622)

12 Wijers SL, Saris WH \& van Marken Lichtenbelt WD. Recent advances in adaptive thermogenesis: potential implications for the treatment of obesity. Obesity Reviews 200910 218-226. (doi:10.1111/j.1467-789X. 2008.00538.x)

13 Ricci C, Longo R, Gioulis E, Bosco M, Pollesello P, Masutti F, Croce LS, Paoletti S, de Bernard B, Tiribelli C et al. Noninvasive in vivo quantitative assessment of fat content in human liver. Journal of Hepatology 199727 108-113. (doi:10.1016/S0168-8278(97)80288-7)

14 Yoneda M, Iwasaki T, Fujita K, Kirikoshi H, Inamori M, Nozaki Y, Maeyama S, Wada K, Saito S, Terauchi Y et al. Hypoadiponectinemia plays a crucial role in the development of nonalcoholic fatty liver disease in patients with type 2 diabetes mellitus independent of visceral adipose tissue. Alcoholism, Clinical and Experimental Research 200731 S15-S21. (doi:10.1111/j.1530-0277.2006.00281.x)

15 Chen YK, Chen YL, Cheng RH, Yeh CL, Lee CC \& Hsu CH. The significance of FDG uptake in bilateral thyroid glands. Nuclear Medicine Communications 200728 117-122. (doi:10.1097/MNM. 0b013e328013eaf7)

16 Iagaru A, Kalinyak JE \& McDougall IR. F-18 FDG PET/CT in the management of thyroid cancer. Clinical Nuclear Medicine 200732 690-695. (doi:10.1097/RLU.0b013e318125037a)

17 Kunawudhi A, Pak-art R, Keelawat S \& Tepmongkol S. Detection of subcentimeter metastatic cervical lymph node by ${ }^{18} \mathrm{~F}$-FDG PET/CT in patients with well-differentiated thyroid carcinoma and high serum thyroglobulin but negative ${ }^{131}$ I whole-body scan. Clinical Nuclear Medicine 201237 561-567. (doi:10.1097/RLU.0b013e318252d30e)
18 Cohade C, Mourtzikos KA \& Wahl RL. "USA-Fat": prevalence is related to ambient outdoor temperature-evaluation with ${ }^{18} \mathrm{~F}$-FDG PET/CT. Journal of Nuclear Medicine $2003 \mathbf{4 4}$ 1267-1270.

19 Truong MT, Erasmus JJ, Munden RF, Marom EM, Sabloff BS, Gladish GW, Podoloff DA \& Macapinlac HA. Focal FDG uptake in mediastinal brown fat mimicking malignancy: a potential pitfall resolved on PET/CT. AJR. American Journal of Roentgenology 2004183 1127-1132. (doi:10.2214/ajr.183.4.1831127)

20 Hany TF, Gharehpapagh E, Kamel EM, Buck A, Himms-Hagen J \& von Schulthess GK. Brown adipose tissue: a factor to consider in symmetrical tracer uptake in the neck and upper chest region. European Journal of Nuclear Medicine and Molecular Imaging 200229 1393-1398. (doi:10.1007/s00259-002-0902-6)

21 Lowell BB, S-Susulic V, Hamann A, Lawitts JA, Himms-Hagen J, Boyer BB, Kozak LP \& Flier JS. Development of obesity in transgenic mice after genetic ablation of brown adipose tissue. Nature 1993366 740-742. (doi:10.1038/366740a0)

22 Liu X, Zheng Z, Zhu X, Meng M, Li L, Shen Y, Chi Q, Wang D, Zhang Z, Li C et al. Brown adipose tissue transplantation improves whole-body energy metabolism. Cell Research 201323 851-854. (doi:10.1038/ cr.2013.64)

23 van-Marken-Lichtenbelt WD, Vanhommerig JW, Smulders NM, Drossaerts JM, Kemerink GJ, Bouvy ND, Schrauwen P \& Teule GJ. Cold-activated brown adipose tissue in healthy men. New England Journal of Medicine 2009360 1500-1508. (doi:10.1056/ NEJMoa0808718)

24 Chen YK, Ding HJ, Su CT, Shen YY, Chen LK, Liao AC, Hung TZ, Hu FL $\&$ Kao CH. Application of PET and PEt/CT imaging for cancer screening. Anticancer Research 200424 4103-4108.

25 Ouellet V, Routhier-Labadie A, Bellemare W, Lakhal-Chaieb L, Turcotte E, Carpentier AC \& Richard D. Outdoor temperature, age, sex, body mass index, and diabetic status determine the prevalence, mass, and glucose-uptake activity of ${ }^{18} \mathrm{~F}$-FDG-detected BAT in humans. Journal of Clinical Endocrinology and Metabolism 201096 192-199. (doi:10.1210/jc.2010-0989)

26 Au-Yong IT, Thorn N, Ganatra R, Perkins AC \& Symonds ME. Brown adipose tissue and seasonal variation in humans. Diabetes $2009 \mathbf{5 8}$ 2583-2587. (doi:10.2337/db09-0833)

27 Quevedo S, Roca P, Pico C \& Palou A. Sex-associated differences in coldinduced UCP1 synthesis in rodent brown adipose tissue. Pflügers Archiv 1998436 689-695. (doi:10.1007/s004240050690)

28 Nedergaard J \& Cannon B. The changed metabolic world with human brown adipose tissue: therapeutic visions. Cell Metabolism $2010 \mathbf{1 1}$ 268-272. (doi:10.1016/j.cmet.2010.03.007)

29 Skarulis MC, Celi FS, Mueller E, Zemskova M, Malek R, Hugendubler L, Cochran C, Solomon J, Chen C \& Gorden P. Thyroid hormone induced brown adipose tissue and amelioration of diabetes in a patient with extreme insulin resistance. Journal of Clinical Endocrinology and Metabolism 201095 256-262. (doi:10.1210/jc.2009-0543)

Received 29 August 2013

Revised version received 30 October 2013

Accepted 18 November 2013 